\title{
Linking relationships between scientists, policy-makers and stakeholders in water management
}

\author{
GD Gooch and P Stalnacke: Science, Policy and Stakeholders in Water Management: An \\ integrated approach to river basin management London: (Earthscan Ltd. London, 2010). \\ pp166. Hard copy.
}

Sustainable water management is now the focus of concern for many different groups in society, including scientists, politicians, water services managers in the public and the private sectors, the public, non-governmental organizations and industrialists. Their concerns are diverse, ranging from, inter alia, the effects of increasing demands on the quantity, quality and economic uses of water, as well as new challenges brought about by global issues such as more sophisticated needs by millions more people at many more localities, urbanization, over-extraction of water from underground aquifers and climate change. History and experience have shown that governments can not do it alone anymore due to the varying diversity and complexity of the water related services in especially the developing world out there.

In this book the following objectives, inter alia, are identified to successfully address and manage the aforementioned challenges:

- The identification and recognition of the ability of a 'leading champion', institution or forum which can facilitate the involvement of all stakeholders;

- bring about optimum visibility, transparency, access and participation at all administrative and sectoral levels, including public policy-making and its implementation; and

- in the final instance integrate the knowledge and experiences from the scientific, policy and stakeholder perspectives in a more efficient manner.

Integrated water resource management (IWRM) has been proposed as a way to address the aforementioned predicament and challenges. Unfortunately a quest to improve the nature and extent of integration needs a deeper understanding of exactly why this integration often proves so difficult to realize, as well as examples of how different groups might be assisted to really work closer together in a more effective, efficient, economic and equal manner. In this book the authors attempt and succeed to do just that, namely, to analyze what integration in water management is about, to unravel some of the main obstacles to this quest to improved integration, and also to provide some good examples from different parts of the world on how integration can be improved.

The authors of the book succeed in identifying the major role-player perspectives from the 'scientists', the public policy-makers and policy-doers, and lastly all the remaining stakeholders' point of view. In order to make the needed integration manifest they identify the need for fully visible, transparent and accessible knowledge and information which can only be realized with improved communication. They also identified the place and role of 'twinning' (the deliberate development of permanent or semi-permanent ties between researchers and practitioners). The 
aforementioned can only be achieved with effective internal and external organizational arrangements of which communication is the most important one.

The research findings on the aspect of integration as key challenge in sustainable water management by means of trans-disciplinary research, are also enlightening and the identified and presented 'lessons learned' and proposed reflections throughout the book are valuable contributions and pointers to fellow researchers and managers in the water services management environment.

It is clear from the book that the authors are masters in the organizational theory terrain in their exposition and highlighting of for example generic aspects from the four case basins of the STRIVER research project regarding aspects such as participation, stakeholder participation per se, social learning, networks and governance and then especially their willingness to come up with very understandable recommendations for improved water services management.

The last chapter of the book gives a very useful summary of common features with reference to the nature and extent of the SPSI processes in the four basins. From these a number of general recommendations concerning methods to improve SPSI in a holistically and integrated water services management quest, are presented which, to me as the novice reader and water services management researcher, is the 'real cherry on top...'

It can be concluded that the authors of this book can be congratulated on the way in which they identify and demonstrate the fundamental sustainable development relationship between scientists, policy-makers, stakeholders as well as the place and role of the facilitating communication, twinning and collaborative interaction. This they did by conveying a breadth of information in a highly accessible and readable text. The book deserves warm recommendation to as wide an audience as possible.

E Nealer

North-West University (Potchefstroom) 